\title{
CASOS DE INOVAÇÃO SOCIAL NA ÍNDIA: DESIGN PARA OS OUTROS 90\%
}

lara D'Ávila Zorzal

Universidade do Estado de Minas Gerais

iarazorzal@gmail.com

Najla Miranda Mouchrek

Virginia Tech

najlammouchrek@gmail.com
Annibal Gouvêa Franco

Universidade do Estado de Minas Gerais

francoartedesign@gmail.com

Maurilio Rabelo Maia

PUC Minas

mauriliodesign@gmail.com

Resumo: O tema do artigo são processos de inovação social na Índia, que configura atualmente um verdadeiro laboratório para desenvolvimento de projetos nesse campo. As enormes desigualdades e graves problemas sociais, políticos e econômicos, aliados a iniciativas de vários atores para pesquisa e desenvolvimento de soluções alternativas, fazem desse país um local promissor para experiências que podem apontar resultados a serem replicados também em outros países. $O$ artigo apresenta fundamentação teórica sobre inovação social, investiga o possível papel do design nesses projetos de inovação e descreve três cases de inovação social na Índia, que visam melhorar as condições de saúde, autonomia e bem-estar, especialmente em relação à população de baixa renda.

Palavras-chave: Inovação Social; Índia; Design para os outros 90\%.

Abstract: The paper focuses on social innovation processes in India, which currently sets up a real laboratory for developing projects in this field. Huge inequalities and serious social, political and economic problems, coupled with initiatives of various actors for research and development of alternative solutions, make this country a promising place for experiences that can point results to be replicated in other countries. The paper presents the theoretical framework of social innovation, investigate the possible role of design in these innovation projects and describes three cases of social innovation in India, aimed at improving health, independence and well -being, regarding especially low income population.

Keywords: Social Innovation, India, Design for the other $90 \%$. 


\section{INTRODUÇÃO}

A inovação social configura-se atualmente como uma tendência crescente, em busca de soluções alternativas para importantes problemas sociais, políticos e econômicos vividos por populações que muitas vezes estão à margem do sistema capitalista e não encontram suporte em políticas públicas ou programas de assistência por parte dos governos. Observa-se essa tendência especialmente nos países em desenvolvimento.

Ao mesmo tempo, o tema é objeto de pesquisa e reflexões acadêmicas, que buscam compreender como se dão as inovações sociais realizadas por esta "maioria silenciosa" que Sachs (2010, p. 25) classifica como a "mais importante categoria social do planeta". São processos muitas vezes intrigantes, tendo em vista que, para se concretizarem novas ideias e sistemas alternativos, são necessários investimentos e recursos que muitas vezes faltam à cerca de $90 \%$ da população mundial. A detenção de poderes por uma minoria tende a formar uma relação de dependência que subjuga e marginaliza a maior parte das pessoas. Além disso, "o mercado (...) é por natureza míope e insensível tanto ao social quanto ao ecológico" (SACHS, 2010, p. 32), o que gera um contexto complexo e insensível às necessidades reais do grosso populacional.

Em busca de um melhor entendimento sobre a inovação social realizada pela maioria mundial que vive com a minoria dos recursos financeiros e sociais, este artigo apresenta três cases de inovação social na Índia. Foram selecionadas situações ligadas ao campo da saúde, um aspecto fundamental do qual grande parte da população do país é extremamente carente. Apresenta-se a fundamentação teórica do trabalho, que envolveu a definição e o estudo aprofundado do conceito de inovação social, características e impacto social das iniciativas em curso, além de uma análise sobre o possível papel do design junto a este novo campo de pesquisa e desenvolvimento.

A seguir, apresenta-se a Índia enquanto um país com características e condições específicas que fazem dele atualmente um verdadeiro laboratório de inovação social. Finalmente, apresentam-se os casos: The Menstrual Men, Embrace e Rural Delivery Health Care.

\section{INOVAÇÃO SOCIAL}

Ideias que funcionam na resolução de problemas sociais e o fazem de forma socialmente relevante (MANZINI, 2010, s.p.).

Os processos de inovação social abrangem "novas estratégias, conceitos e métodos para atender necessidades sociais" (BATHOLO, 2008, p.5), podendo ser aplicados a campos como educação, saúde, lazer, trabalho, saneamento básico, melhorias das condições de vida e de convivência, entre outros.

Inovações sociais são ao mesmo tempo boas para a sociedade e fortalecem sua capacidade de agir, na medida em que as "novas ideias, produtos, serviços e modelos simultaneamente atendem às necessidades sociais e criam novos relacionamentos sociais e colaborações" (MURRAY, CAULIER-GRICE e MULGAN, 2006, p.3). 


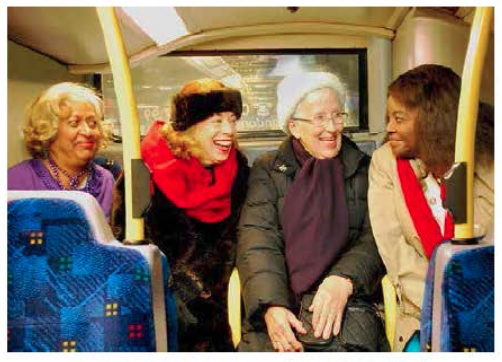

Círculos de cuidado (ajuda mútua)

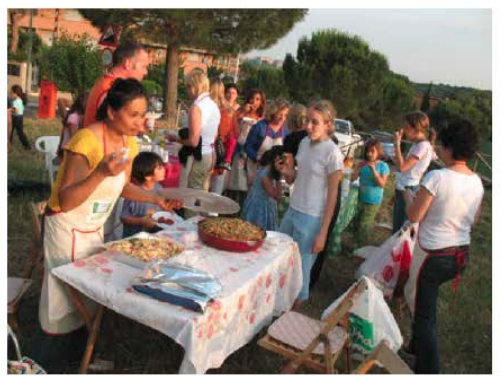

Comunidades ativas (Itália)

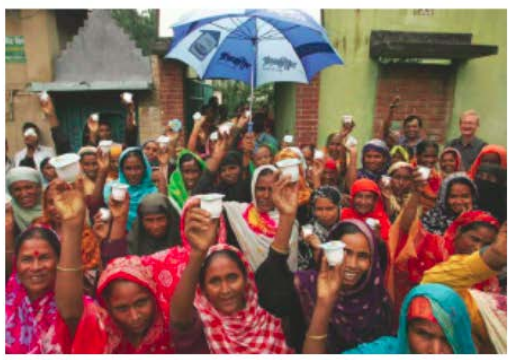

Geração de alternativas de renda (Bangladesh)

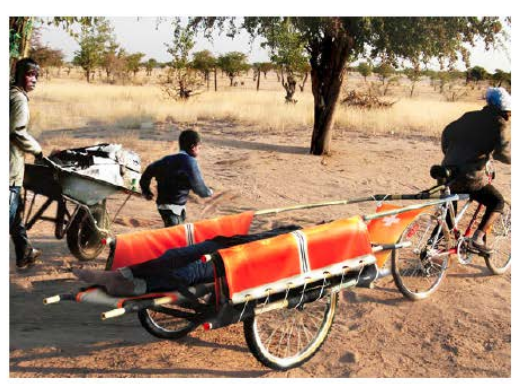

Bambulance (Design for Development Society)

Figura 1 - Exemplos de iniciativas de inovação social, em diversos países.

Adaptado de MANZINI, 2010; BAMBULANCE, 2008)

É importante notar um fator fundamental nesses processos de mudança: as novas ideias são geradas pelos atores diretamente envolvidos nos problemas a serem resolvidos (MANZINI, 2010). Em todo o mundo, emergem iniciativas espontâneas de inovação social, conduzidas pelo esforço de um número crescente de pessoas que, enfrentando problemas diários, buscam soluções viáveis para problemas complexos da atualidade e criam novos modos de vida sustentáveis (MERONI, 2007; MANZINI, 2008).

\section{1 - Casos de Inovação Social: características}

Em todo o mundo, centenas de milhares de pessoas estão experimentando novas formas de viver e produzir (MANZINI, 2010, s.p.).

A inovação social está gerando novas visões e conduzindo a novos modelos. (Manzini, 2010). As iniciativas podem apresentar-se em diferentes configurações, enquanto processos sociais de inovação; inovações de interesse social; empreendedorismo de interesse social e/ou suporte da ação inovadora (BATHOLO, 2008, p.5).

Encontram-se inúmeros exemplos de iniciativas de inovação social sendo desenvolvidas em diversos países. É possível classificá-las em diferentes grupos, de acordo com a natureza das soluções que propõem: 
Quadro 1 - Exemplos de iniciativas de inovação social, classificadas segundo a natureza das soluções propostas.

\begin{tabular}{|c|c|}
\hline Natureza das soluções & Exemplos de iniciativas de inovação social \\
\hline $\begin{array}{l}\text { Melhoria / regeneração da qualidade de } \\
\text { vida em diversos contextos (saúde, } \\
\text { saneamento, moradia, alimentação, } \\
\text { educação) }\end{array}$ & $\begin{array}{l}\text { Alternativas para ampliar atendimento de saúde na área } \\
\text { rural, soluções para viabilizar transporte de pessoas para } \\
\text { hospitais e escolas, uso da tecnologia para soluções viáveis } \\
\text { e baratas de tratamento de saúde e saneamento básico, } \\
\text { agricultura comunitária e armazenamento de sementes. }\end{array}$ \\
\hline $\begin{array}{l}\text { Desenvolvimento de soluções } \\
\text { habilitantes (empoderamento e } \\
\text { condições de autonomia), criação e } \\
\text { fortalecimento de instrumentos de } \\
\text { governança participativa }\end{array}$ & $\begin{array}{l}\text { Criação de moedas locais e microfinanciamento, turismo } \\
\text { de base comunitária, comércio justo, incubadoras sociais, } \\
\text { cooperativos de alimentos, formação para mercado de } \\
\text { trabalho, feiras de troca, estímulo ao crescimento e busca } \\
\text { de produtores locais }\end{array}$ \\
\hline $\begin{array}{l}\text { Projetos de ajuda mútua, cuidado e } \\
\text { bem-estar coletivo }\end{array}$ & Círculos de cuidado entre idosos, micro-creches \\
\hline $\begin{array}{l}\text { Novas propostas de ocupação e uso dos } \\
\text { espaços públicos }\end{array}$ & $\begin{array}{l}\text { Jardins e hortas comunitários, mutirões para limpeza e } \\
\text { construção em espaço público }\end{array}$ \\
\hline $\begin{array}{l}\text { Uso equilibrado de recursos, bens e } \\
\text { serviços }\end{array}$ & $\begin{array}{l}\text { Cohousing, car sharing, bibliotecas de ferramentas, } \\
\text { empréstimo rotativo de bicicletas }\end{array}$ \\
\hline $\begin{array}{l}\text { Resgate das tradições como recursos } \\
\text { sociais importantes e fortalecimento da } \\
\text { comunidade }\end{array}$ & $\begin{array}{l}\text { Festivais de rua, resgate de saberes tradicionais (culinária, } \\
\text { artes manuais, cura pelas plantas etc), iniciativas que } \\
\text { promovem partilha de conhecimentos entre diferentes } \\
\text { gerações }\end{array}$ \\
\hline
\end{tabular}

O denominador comum entre os casos é que representam diversas formas de mudanças radicais na escala local (MANZINI, 2008, p. 63). São rupturas com a maneira habitual de pensar e agir naqueles contextos e tentativas de aplicar novos modos em busca de maior equilíbrio, equanimidade, eficiência e sustentabilidade.

Outro fator importante a observar nos casos de inovação social é sua capacidade de articular interesses individuais $e$ os interesses sociais e ambientais (MANZINI, 2008, p. 63): na busca de soluções concretas, terminam por reforçar o tecido social e colocar em prática esquemas mais sustentáveis e novas concepções de bem-estar.

Criatividade é outro aspecto indispensável para a inovação social, tendo em conta que em muitos casos, verifica-se uma ação criativa típica: reorganizar elementos já existentes em novas e significativas combinações (MANZINI, 2008, p. 64).

Outro fator de análise é o princípio de utilização de tecnologias habilitantes (MANZINI, 2008, p. 67): iniciativas que fazem uso das tecnologias disponíveis de uma maneira original para gerar produção e serviços diferenciados, que atendam a necessidades sociais e habilitem pessoas e processos inovadores.

Grande parte dos processos de inovação social em curso aponta para um novo tipo de economia, que pode ser descrita como "economia social", que tem como pontos-chave (MURRAY, CAULIER-GRICE e MULGAN, 2006, p. 5):

- o uso intensivo de redes distribuídas para sustentação e administração (uso de estruturas de comunicação ampliadas e ferramentas de redes sociais);

- fronteiras difusas entre produção e consumo (o consumidor passa de um papel passivo a outro ativo; 
- ênfase na colaboração e em interações frequentes, cuidado e manutenção, ao invés de ênfase no consumo;

- valores e missões têm papel fundamental (ênfase crescente na dimensão humana).

Destaca-se também a importância das qualidades relacionais. Em sua maioria, a inovação social relaciona-se com a criação e fortalecimento de organizações colaborativas, em níveis variados (serviços, empreendimentos e/ou redes de cidadãos colaborativos). Em todos os casos, o elemento comum é sua constituição por "grupos de indivíduos que colaboram entre si na co-criação de valores comumente reconhecidos e compartilhados" (MANZINI, 2008, p. 71).

\subsection{O papel do Design}

O estudo dos casos de inovação social, especialmente inovações sociais de base na vida cotidiana, demonstra que as habilidades difusas de design, ligadas a modos de pensar e agir não convencionais, de base criativa e coletiva (MANZINI, 2008, p. 17), são capazes de criar descontinuidades e desenvolver novos processos de aprendizagem social, fundamentais para uma efetiva mudança sustentável.

Considera-se a criatividade e as habilidades de design como elementos "efetivamente necessários para mover um processo de novação social e tecnológica como requer a transição rumo à sustentabilidade "(MANZINI, 2008, p.16)

Nos processos de inovação social, é gerado um tipo original de redes de Design: "grupos amplos e flexíveis de agentes sociais que criam e desenvolvem colaborativamente soluções sustentáveis" (MANZINI, 2008, p. 97-98). Os designers são parte destas redes de Design emergentes e devem colaborar oferecendo suas competências específicas e alimentar essas redes de Design com seus conhecimentos profissionais, interagindo com outros designers não profissionais em um modelo de parceria (KRUCKEN, 2008, p. 28-29).

O design pode configurar um importante agente propulsor para os processos de inovação social, na medida em que a inovação conduzida pelo design pode promover, facilitar e ampliar as iniciativas colaborativas em seus diferentes aspectos. O design pode participar: promovendo novos cenários, desenvolvendo ferramentas e infraestrutura de apoio, estabelecendo condições para o contexto criativo, nutrindo redes, facilitando a convergência e trabalhando para regenerar a qualidade do contexto (KRUCKEN, 2008; MERONI, 2007; MALAGUTI, 2009; MANZINI, 2008; MARGOLIN, 2007).

O foco projetual do Design evolui em direção a uma perspectiva sistêmica, aumentando seu campo de ação. Assim, é fundamental para o designer desenvolver competências para ser um facilitador no processo de inovação, promovendo formas de colaboração e participação ativa: integrar, ativar diálogos, criar conexões - ao mesmo tempo contextualizar e globalizar (KRUCKEN, 2008, p. 29).

\section{3. ÍNDIA: UM LABORATÓRIO DE INOVAÇÃO SOCIAL}

O conjunto da sociedade contemporânea, em sua complexidade e contraditoriedade, pode ser visto como um imenso laboratório de ideias para a vida cotidiana, onde modos de ser e de fazer se desdobram em novas questões e respostas inéditas (MANZINI, 2008, p. 62). 
A Índia configura um contexto atual e muito interessante, um verdadeiro laboratório de inovação social (ELKINGTON, 2013, s.p.).

A Índia é um país de muitas riquezas e muitos contrastes. Configura uma sociedade pluralista, multilíngue e multiétnica. Localizado na Ásia Meridional, é o segundo país mais populoso, o sétimo maior em área geográfica e a democracia mais populosa do mundo.

A civilização indiana é uma das mais antigas do mundo tendo surgido há mais de 4000 anos. A região foi conquistada pelos arianos, que implantaram uma sociedade baseada num sistema de castas. Colonizada pela Inglaterra, tornou-se independente em 1947 e tem sido uma democracia desde então. Atualmente, a Índia é uma república parlamentarista, com dois idiomas oficiais e uma população de aproximadamente um bilhão de pessoas. (BARCELLOS, DIAS e DIAS, 2005, p. 718-719).

A Índia possui uma atividade industrial expressiva. Na agricultura, os principais produtos cultivados são: chá, algodão, trigo, juta, arroz, tabaco, milho e cana-deaçúcar. Existem grandes áreas com monoculturas voltadas para a exportação. São as plantations, cultivadas desde a época em que os ingleses colonizaram essa região. Nos últimos anos, a Índia tornou-se um importante centro de serviços relacionados com tecnologias de informação.

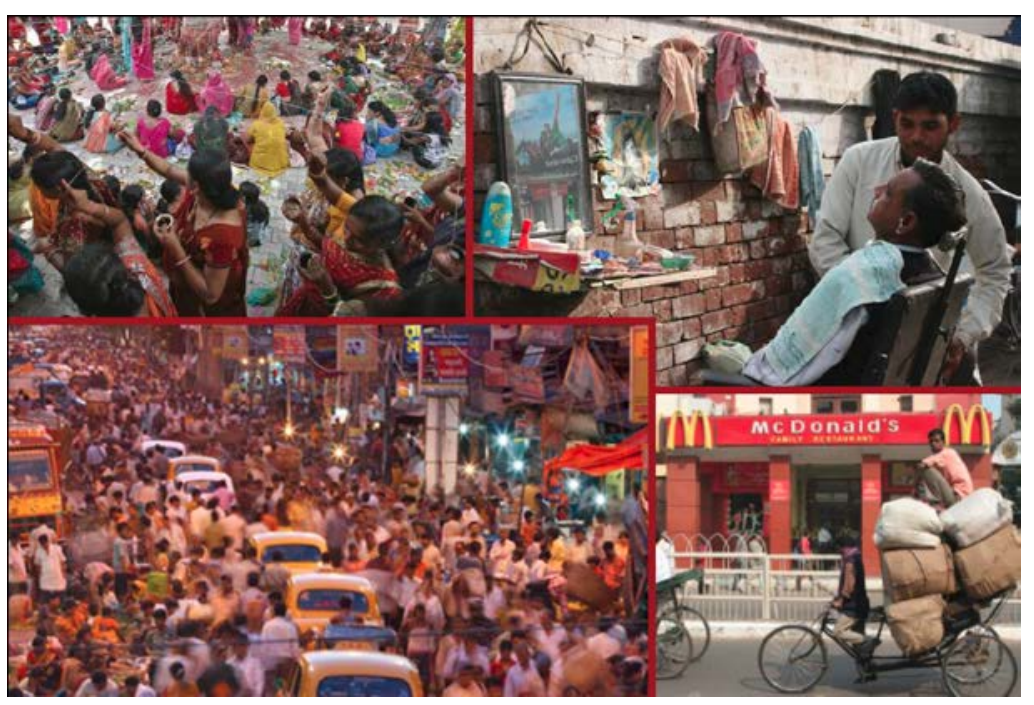

Figura 3 - Índia, um país de contrastes - Cultura.

Adaptada pelos autores a partir de arquivos de bancos de imagens.

Apresenta uma das economias de mais rápido crescimento do mundo, com notáveis índices nas últimas décadas. No entanto, a Índia ainda sofre com altos níveis de pobreza, analfabetismo, doenças e desnutrição, imensas diferenças regionais e dificuldades com o sistema de representação política e o processo decisório.

Por um lado, com sua imensa população, o alto grau de desigualdade social e econômica e a dificuldade de solução de problemas básicos, e por outro, com o potencial tecnológico, acadêmico e empreendedor que apresenta atualmente, a Índia representa um contexto bastante propício para a inovação social. Neste contexto, destacam-se (SHANMUGALINGAM, 2009, s.p.):

- Grandes problemas sociais; 
- Governo corrupto e nenhum comissionamento do poder público;

- Legalidade questionável das instituições de microfinanciamento;

- Crescimento econômico rápido e confuso (=10\%);

- Crescimento rápido do consumismo e pouca segurança do trabalho no setor privado;

- Empreendedores sociais realmente competentes e proativos .

Por essas razões, considera-se que a Índia pode se tornar um modelo para inovações na resolução de problemas em escala global (INDIA+SOCIAL GOOD , 2014).

Analisando as condições atuais para desenvolvimento de inovação social no país, Elkington aponta um fator promissor: a existência de uma nova geração de empreendedores para quem a inovação é uma solução escalonável e um negócio rentável, ainda que fins lucrativos não sejam a principal motivação. Por outro lado, o autor aponta também uma preocupação com a corrupção política no país: sem apoio do governo e financiamento, empreendedores são forçados a lidar com objetivos estreitos e de curto prazo, o que limita as potencialidades da inovação social (ELKINGTON, 2013, s.p.).

A seguir, apresentam-se três cases de inovação social na Índia, todos ligados à busca de soluções inovadoras no campo da saúde.

\subsection{The Menstrual Man: o homem que adotou um 'útero' e iniciou uma revolução na Índia}

Inovação é, portanto, focada no [...] melhoramento das soluções fornecidas por produtos, permitido por uma melhor análise de seus usuários (VERGANTI, 2009, p.15, tradução nossa).

Inspirado no documentário The Menstrual Man, este case conta a história de Arunachalam Muruganantham, um indiano de origem pobre e sem estudos, que decidiu descobrir como produzir absorventes com preços mais acessíveis.

O fato propulsor para a inovação de Muruganantham foi a constatação de que sua mulher, Shanthi, utilizava trapos de tecido para contenção de sua menstruação. 0 indiano ficou chocado com a realidade da mulher, que em 1998 ainda se valia de um método extremamente rústico. Em resposta aos seus questionamentos, Shanthi explicou-lhe que a maioria de suas conterrâneas se valia dos mesmos métodos, pois o absorvente higiênico é extremamente caro para suas economias.

O argumento da esposa foi comprovado por uma pesquisa, encomendada pelo governo indiano e realizada em 2011 pela AC Nielsen, que constatou que apenas 12\% das mulheres do país utilizavam absorventes. Em sua busca para compreender a verdadeira situação do país, Muruganantham descobriu que além dos trapos de tecido, as mulheres utilizam areia, serragem, folhas e até cinzas para ajudar na contensão do fluxo e evitar vazamentos.

Além da situação financeira, há também na Índia a questão cultural de que homens não podem sequer ver os paninhos das mulheres da casa. Sendo assim, estes não devem ser colocados para secar ao sol, junto com as outras roupas, levando-os a serem muitas vezes reutilizados ainda úmidos. Por não desinfetarem corretamente os panos e utilizarem-nos com substâncias anti-higiênicas, as indianas desenvolvem diversas doenças na região uterina e urinária. De acordo com as autoridades de saúde do país, aproximadamente $70 \%$ de todas as doenças reprodutivas na Índia são 
causados por falta de higiene menstrual, havendo, também, influência na mortalidade materna.

A barreira cultural foi um dos maiores problemas a ser enfrentado por Muruganantham, que durante o processo de desenvolvimento do absorvente foi abandonado por sua esposa e sua mãe, além de não conseguir voluntárias para participarem de sua pesquisa. $O$ indiano depõe no documentário sobre sua dificuldade para conseguir compreender a fundo o processo menstrual feminino, afinal não adiantava ler em um livro, era preciso vivenciar. Seu último recurso foi recorrer às estudantes de medicina para serem voluntárias, estas porém falsificavam os questionários por vergonha de respondê-los.

O inventor então decidiu realizar experiências em si mesmo; para isso ele precisou simular uma menstruação. Ele criou um 'útero' a partir de uma bola de futebol, na qual fez vários furos e enchia com sangue de cabra a cada experiência. "Eu me tornei o homem que usava um absorvente" (MURUGANANTHAM, 2013).

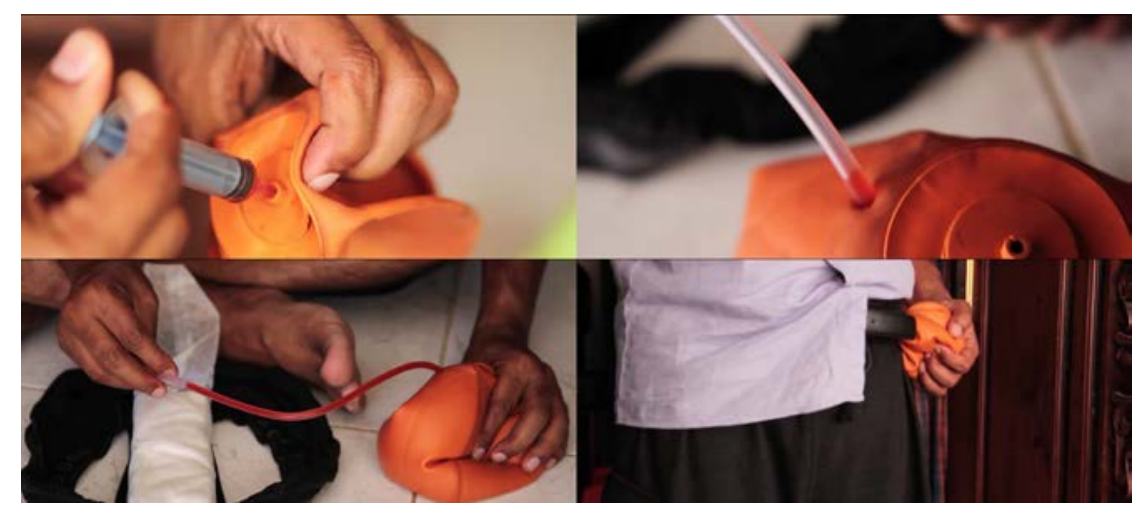

Figura 4 - Demonstração do funcionamento da bomba menstrual.

Fonte: Documentário The Menstrual Men (2013).

Muruganantham conseguia o sangue com um amigo açougueiro; o aditivo que utilizava para evitar a rápida coagulação era cedido por outro amigo que trabalhava no banco de sangue. Ele caminhava, pedalava e corria com a bexiga de futebol debaixo de suas roupas tradicionais, constantemente bombeando sangue para testar as taxas de absorção do absorvente que desenvolvera. O indiano também analisava absorventes usados, em busca de compreender como os de sucesso eram feitos. Sua obsessão por uma resposta, juntamente ao seu constante "sangramento", levaram-no a ser expulso de sua comunidade.

Após dois anos e três meses de testes e pesquisas, ele conseguiu descobrir o insumo necessário para que o absorvente funcionasse: celulose retirada de casca de árvore. O próximo passo foi desenvolver o maquinário necessário para a produção de seu produto, pois os já existentes no mercado eram extremamente caros. Mais quatro anos e meio se passaram e Muruganantham, finalmente, havia conseguido criar um método de baixo custo para a produção de absorventes.

Depois de tantos anos e pesquisas, o objetivo do indiano não era mais somente prover absorventes baratos para as indianas - ele decidiu gerar emprego e proporcionar a elas autonomia financeira. Sendo assim, desenvolveu uma máquina prática, fácil de usar e que se assemelha às máquinas rurais manuseadas por mulheres diariamente. Longe de querer disputar com as multinacionais, Muruganantham 
pretendia adentrar em um novo mercado, no qual seus produtos eram necessários mas ninguém os provia.

Diante de tal invenção o Instituto de Tecnologia Indiano resolveu inscrever, sem seu consentimento, a máquina de Muruganantham em um prêmio nacional de inovação. Entre os 943 investidores, sua inovação ficou em primeiro lugar, modificando totalmente o cenário até então enfrentado. $O$ indiano passou a ser aceito nas comunidades, conseguiu apoio de empresas, foi nomeado como uma das 100 mentes mais influentes do mundo e até mesmo pôde ter sua esposa de volta.

Suas máquinas já atingiram 1.300 aldeias, em vinte e três estados. São as mulheres que produzem, vendem e explicam às usuárias como a máquina funciona e a necessidade do uso. Muitas vezes, os absorventes são vendidos em troca de batatas, cebolas ou outro produto. Sendo assim, um sistema de troca foi desenvolvido por cada aldeia, de forma a permitir o acesso do maior número possível de mulheres. A invenção de Muruganantham conseguiu reduzir o valor unitário dos absorventes à metade, sendo os lucros utilizados para manutenção das máquinas, pagamento de salários e continuidade dos trabalhos.

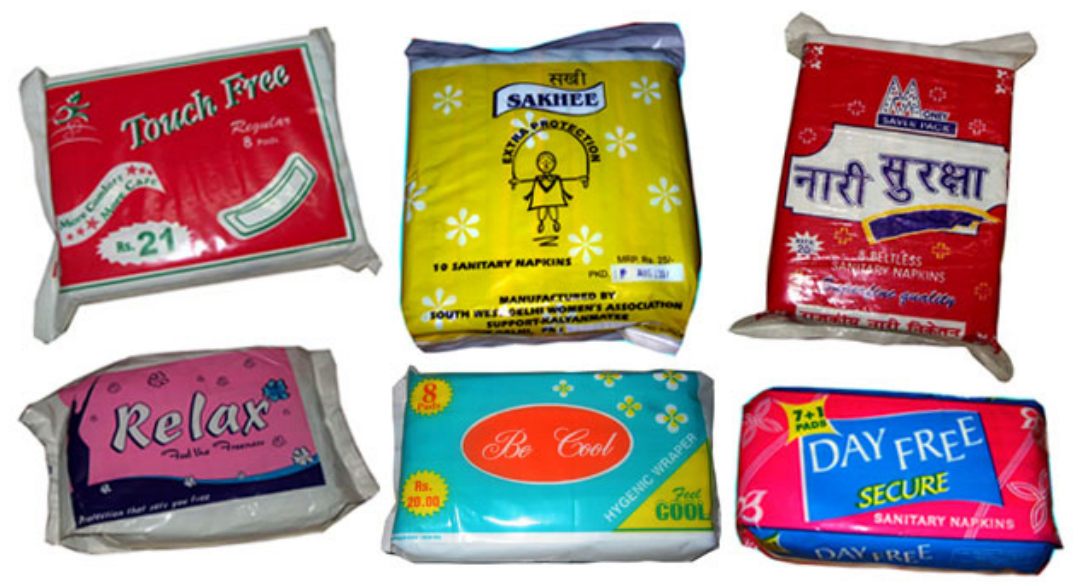

Figura 5 - Pacotes de absorvente de várias cooperativas iniciadas por Muruganantham, que dá total liberdade a cada uma de criar sua própria logo e embalagem.

Fonte: Documentário The Menstrual Men (2013).

Os maiores clientes do inventor são ONG's e grupos de ajuda mútua feminina. Para além das áreas rurais, o indiano está desenvolvendo um trabalho diretamente com as escolas do país. Isso porque, $23 \%$ das meninas abandonam a educação logo que menstruam. O objetivo é ensinar a elas como manusear os absorventes e acabar com o mito de que é necessário se esconder em casa durante os cinco dias do ciclo.

Meu objetivo era criar um milhão de postos de trabalho para as mulheres pobres, mas por que não 10 milhões de empregos em todo o mundo? (MURUGANANTHAM, 2013)

Muruganantham ainda tem muito a enfrentar, em locais com péssimas condições de instalação e uma política corrupta, que não apoia seus conterrâneos. Mesmo assim, o indiano mantém sua persistência e pretende avançar com sua invenção pelo mundo, expandindo o modelo para 106 países, incluindo Quênia, Nigéria, Filipinas e Bangladesh. 
Ao contrário do que muitos o instigam a fazer, Muruganantham recusou-se a patentear sua máquina e também não aceita vendê-la para grandes multinacionais. Seu objetivo é ajudar as mulheres de seu país e do mundo e não enriquecer. Além disso, se ele fizesse acordos com grandes empresas, seus produtos não poderiam mais ser trocados e, sim, apenas comprados com dinheiro, o que afetaria a principal filosofia de suas cooperativas.

\subsection{Embrace: uso inovador da tecnologia a serviço da vida}

Estatísticas apresentadas pela Organização Mundial de Saúde em 2004 atestam que todos os anos nascem no mundo vinte milhões de bebês com baixo peso, muitas vezes consequência de um parto prematuro (OMS, 2004). Este fato contribui para a elevação da taxa de mortalidade neonatal, ainda existente em várias regiões, principalmente nos países pobres.

Neste sentido, o referido relatório de pesquisa (OMS, 2004) explica que a prematuridade provoca hipotermia, além de aumentar as chances do contágio de infecções hospitalares. Assim, uma das importantes recomendações do relatório é que, a cada vez tornar-se-ão mais necessários cuidados para atender às necessidades do bebê em relação a calor e proteção.

De acordo com Cruvinel e Pauletti (2009), é considerado prematuro o bebê nascido com menos de vinte e sete semanas de gestação, e com baixo peso, o bebê que pese menos de $2500 \mathrm{~g}$. Ao nascerem antecipadamente, os bebês apresentam imaturidade dos órgãos e sistemas, acarretando em atraso no desenvolvimento neuropsicomotor. Os bebês prematuros frequentemente necessitam permanecer por vários dias em uma incubadora neonatal, sob cuidados especiais. Os bebês são assim mantidos até completarem o seu desenvolvimento (CRUVINEL e PAULETTI,2009; LAMY et al, 2005).

As incubadoras possuem um alto custo, e para tentar reverter os índices de mortalidade de bebês prematuros na Índia, a multinacional americana GE e o Instituto de Design de Stanford desenvolveram incubadoras ${ }^{1}$ de baixo custo que estão salvando vidas.

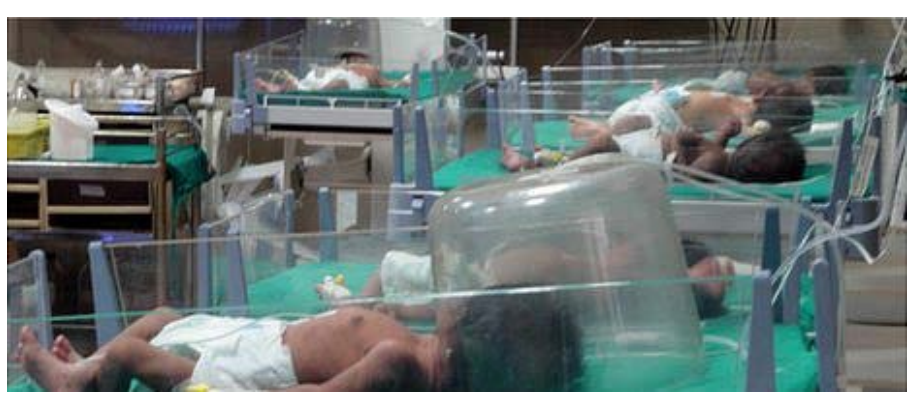

Figura 6: Baby Warmer.

Fonte: $B B C$ News - Baby Warmer.

Elaborado pela GE em Bangalore, em 2009, o Baby Warmer custa US\$3 mil (cerca de $\mathrm{R} \$ 7,5 \mathrm{mil}$ ) na Índia. O produto é $70 \%$ mais barato do que os modelos tradicionais, e necessita de eletricidade constante para o seu funcionamento.

\footnotetext{
${ }^{1}$ Disponível em: <http:// www.bbc.com/news/business-23817127/>. Acesso em: 25 mai. 2014.
} 
Em 2011, um novo produto passou a ser produzido. Nomeado Embrace Warmer, este possui um custo mais baixo do que o anterior (somente US\$200 a sua fabricação), e independe de uma constante fonte de energia elétrica para o seu funcionamento.

Segundo Mccarthy (2013), o produto consiste em um envoltório para o bebê, com um compartimento específico para introduzir uma bolsa de plástico, aquecida. A bolsa possui uma cera que se torna líquida ao ser esquentada a $98.6^{\circ} \mathrm{F}$, ou seja $37^{\circ} \mathrm{C}$, o calor dissipa-se ao longo de quatro a seis horas, mantendo a criança aquecida neste período.

Ainda segundo o autor, a bolsa de cera pode ser esquentada utilizando água quente ou eletricidade; o processo dura aproximadamente 25 minutos. 0 envoltório pode ser reutilizado inúmeras vezes e, quando necessário, ser lavado mais de cinquenta vezes.

A Embrace ${ }^{2}$ começou como um projeto acadêmico na Universidade de Stanford - Califórnia, em 2007, quando um grupo de estudantes universitários foi desafiado a projetar uma intervenção de baixo custo para a hipotermia neonatal.

Em junho de 2009, a equipe responsável pelo desenvolvimento do Embrace instalou-se em Bangalore, devido à cultura empreendedora em expansão na cidade e às altas taxas de mortalidade infantil da Índia. Bangalore é capital e a maior cidade do estado de Karnataka, localizado no sul do país.

Ainda em 2009, após uma extensa fase de prototipagem, iniciaram-se os testes com o produto. O primeiro teste envolveu um boneco humano com sensores, com o objetivo de monitorar os sinais vitais simulados.

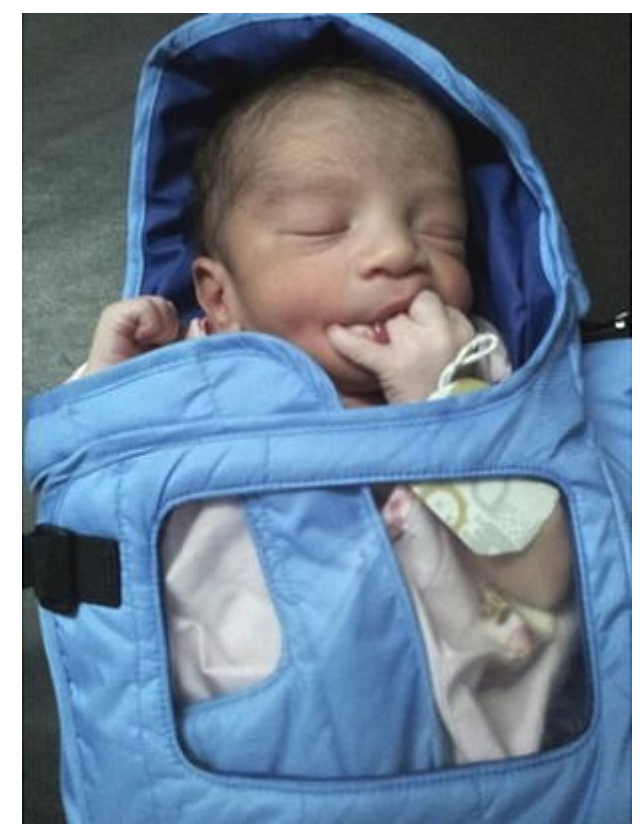

Figura 7: Embrace Warmer.

Fonte: $B B C$ News - Embrace Warmer.

${ }^{2}$ Disponível em: <http://embraceglobal.org/>. Acesso em: 25 mai. 2014. 
Em 2011, foi iniciada a produção do Embrace Warmer, com valor inferior a $1 \%$ daquele da incubadora-padrão, que possui ainda as características: é portátil, higiênico e reutilizável.

Em janeiro de 2012, a empresa Embrace anunciou uma nova estrutura organizacional. Além da Embrace, foi fundada a Embrace Innovations: uma empresa social reservada para fins lucrativos, criada para lidar com o projeto, fabricação e execução de testes clínicos da incubadora, assim como as vendas para os governos e clínicas privadas.

Em 2013, o The Economist ${ }^{3}$ premiou os co-fundadores da Embrace como vencedores do prêmio Inovação de 2013 na categoria Inovação Econômica e Social, e dispõe em seu website que mais de 20.000 bebês em uma dúzia de países beneficiaramse com o seu design.

\subsection{Rural Delivery Healthcare: Inovação no serviço de saúde indiano}

O Rural Delivery Healthcare indiano é um sistema constituído de uma plataforma Open Source integrada a uma base de dados, que tem por objetivo ampliar a entrega de saúde para a população rural indiana. Um sistema de saúde centralizado é ineficaz junto a esta população, que tem suas particularidades setorizadas por províncias.

O propósito do sistema está alicerçado em três premissas principais: reduzir a mortalidade infantil, ampliar os cuidados da saúde da mulher e minimizar ocorrências de epidemias. Se comparadas a dados de outros países, as estatísticas nos quadros básicos de saúde da Índia evidenciam a importância e urgência do governo indiano em buscar formas inovadoras de ampliar a abrangência do atendimento da população.

Com o programa do Rural Delivery Healthcare, cada centro de saúde local pode desenvolver suas próprias soluções para realizar a entrega de saúde para a população Local baseadas nos contextos regionais.

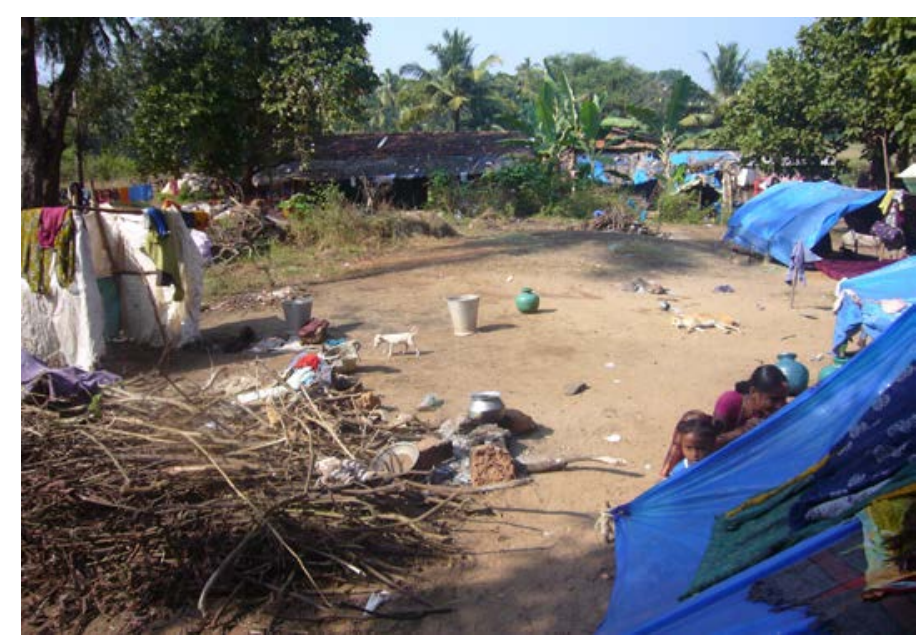

Figura 8: Comunidade rural indiana.

Fonte: Disponível em http://collaborativelines.com/tag/india.

Um case de sucesso dentro do programa é o SughaVazhvu Healthcare, localizado na província de mesmo nome. A partir da plataforma Open Source integrada

\footnotetext{
${ }^{3}$ Disponível em: <http://embraceglobal.org/>. Acesso em: 25 mai. 2014.
} 
ao sistema de informação de dados de saúde nacional, foi possível implementar um sistema de entrega de saúde que conta com uma base de dados em nuvem integrada a dispositivos com tecnologia mobile de custo acessível. Os dados são coletados nas unidades de saúde ou pelos agentes e alimentados progressivamente. Indicadores principais são inseridos digitalmente no sistema, e agregados para fornecer um retrato estatístico de indicadores de saúde na Índia em cada nível do sistema: blocos, comunidades, províncias, estados e nação. A qualidade dos dados é verificada através de um processo de triangulação que valida as informações dadas.

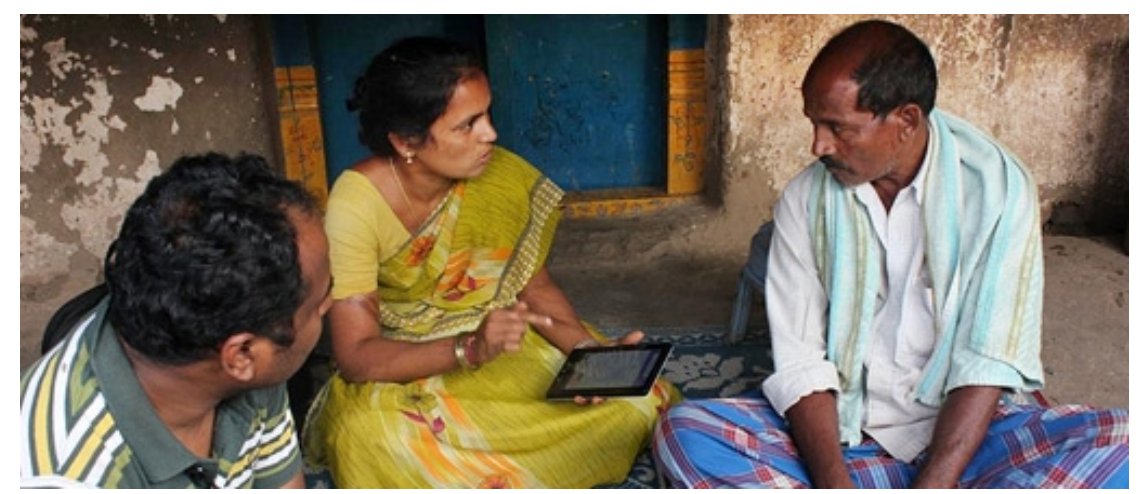

Figura 9: Utilização de tecnologia mobile no sistema Rural Delivery Healthcare.

Fonte: Disponivel em http://www.georgeinstitute.org.in/news/dr-praveen-wins-imedical-apps-andmedicine-20-mhealth-award-2013-for-smarthealth-india-project. Acesso em 18 de junho de 2014.

Segundo dados da Nasscom Foundation, foram treinados 10.000 agentes de saúde para utilização da plataforma em seus smartphones que atuaram em regiões rurais e realizaram geo-marcações de 65.000 indivíduos que se cadastraram no aplicativo. Tais feitos garantiram ao SughaVazhvu Healthcare o prêmio ICT Led Social Innovation by a Not for Profit Organization, promovido pela Nasscom Foundation em 2014.

\section{CONCLUSÃO}

Nos casos estudados, foi possível observar a presença de várias características da inovação social descritas na fundamentação teórica. Apresentam-se a seguir as mais relevantes para esse estudo.

A máquina de produção de absorventes de Muruganantham ("Menstrual Men") aponta para um novo tipo de economia ("economia social", cf. MURRAY, CAULIERGRICE e MULGAN, 2006), na medida em que:

- $\quad$ as mulheres são ao mesmo tempo produtoras e consumidoras;

- cria e estimula um sistema de produção e comercialização que têm ênfase na colaboração, nas interações pessoais e na manutenção frequente da rede de contatos;

- a dimensão humana tem valor fundamental, já que é uma solução desenvolvida por um homem do povo, pensando na melhoria de condições para suas semelhantes.

Os projetos apresentados nos casos Embrace e Rural Delivery Healthcare operam a partir do princípio de utilização de tecnologias habilitantes (MANZINI, 2008, p.67), na medida em que: 
- desenvolvem novas maneiras de utilizar tecnologias já existentes para otimizar processos em regiões extremamente carentes;

- ao mesmo tempo atendem necessidades sociais e habilitam as próprias pessoas a se tornarem mais autônomos e coletivamente desenvolverem soluções para suas questões.

Nos três casos, constata-se a presença da criatividade, já que lançam mão de recursos em combinações inovadoras:

- Menstrual Men - propõe o empoderamento feminino a partir de um sistema novo de produção dirigido por elas: o que antes era um fator desabilitante (a menstruação e a ausência de formas de contenção) torna-se exatamente seu fator habilitante (autonomia financeira e participação relevante na comunidade).

- Embrace: propõe, a partir de tecnologia e pesquisa acadêmica, um produto inovador que muda radicalmente as condições de sobrevida dos bebês com pouca dependência da energia elétrica, permitindo às famílias pobres cuidarem bem melhor de sua família com seus próprios recursos;

- Rural Delivery Healthcare: propõe utilizar tecnologias de comunicação para criar uma ampla rede de informação na área rural e assim otimizar significativamente o atendimento de saúde.

Também nos três casos, o fator qualidade relacional está presente, na medida em que, cada um em seu nível, operam visando a criação e fortalecimento de organizações colaborativas.

Considera-se que o design está presente nos três casos, tendo em vista que, embora não contem com designers profissionais em suas equipes, utilizam estratégias, ferramentas de pesquisa e desenvolvimento em design em diferentes níveis. Entre elas, lista-se:

- Menstrual Men: análise de contexto, desenvolvimento de protótipo, teste de usabilidade, redesign alternativo de processo de produção.

- Embrace: redesign de produto, desenvolvimento de solução com baixa intensidade de energia e material, criação de rede de usuários diferenciada.

- Rural Delivery Healthcare: codesign, arquitetura e dinâmica de rede de informações, design da experiência do usuário.

A pesquisa comparada dos casos demonstrou na prática a ideia da Índia como um laboratório de inovação social: as enormes desigualdades e graves problemas sociais, políticos e econômicos, aliados a iniciativas de vários atores para pesquisa e desenvolvimento de soluções alternativas, fazem desse país um local promissor para experiências que podem apontar resultados a serem replicados também a outros países. Muitos outros países em desenvolvimento já começam a se beneficiar das soluções desenvolvidas por estes três projetos.

Analisando as informações encontradas, atesta-se que o design está presente de várias formas e que os projetos, tanto aqueles já bem sucedidos quanto aqueles que se encontram em fase inicial, poderiam se beneficiar muito com a participação de designers profissionais nas equipes multidisciplinares, de forma a agregar suas competências e habilidades nas soluções e projetos inovadores. 


\section{REFERÊNCIAS}

BAMBULANCE. Disponível na internet por $<$ http://www.plippo.com/client/bambulance/home.html>. Acesso em 21 de novembro de 2013.

BARCELLOS, Kátia; DIAS, Marcus R.; DIAS, Simone M. Brasil e Índia: um paralelo do desenvolvimento econômico e social. II Simpósio de Excelência em Gestão e Tecnologia, 2005

CHAVALI, Annapurna e ANUPINDI, Ravi. Healthcare Delivery in Rural India -ITC experience. Disponível na internet por:

http://www.accessh.org/CaseStudies_Pdf/ITC_and_healthcare_CHMI.pdf. Acesso em 18 de junho de 2014.

CRUVINEL, Fernando Guimarães e PAULETTI, Claremir Maria. Formas de atendimento humanizado ao recém nascido pré-termo ou de baixo peso na unidade de terapia intensiva neonatal: uma revisão. Cadernos de Pós-Graduação em Distúrbios do desenvolvimento, v. 9, n. 1, p. 102-125, 2009.

ELKINGTON, John. India, a laboratory of social innovation. Entrevista a Pankti Mehta. Hisdustan Times, 2013. Disponível na internet por http://www.hindustantimes.com/entertainment/interviews/india-a-laboratory-ofsocial-innovation/article1-988068.aspx. Acesso em: 15 de abril de 2013.

Embrace Warmer. Disponível na internet por <http://embraceglobal.org $>$. Acesso em 25 de maio de 2014

Financial Express (revista). Disponível na internet por http://healthcare.financialexpress.com/201205/itathealthcare02.shtml. Acesso em 18 de junho de 2014.

IBEF India. Disponível na internet por http://www.slideshare.net/IBEFIndia/healthcare-august-2013. Acesso em 18 de junho de 2014.

Índia + Social Good (Vídeo). Disponível na internet por <http://www.youtube.com/watch?v=rOjacJOaXsA>. Acesso em 17 de abril de 2014.

India Social Good. Disponível na internet por <http://www.socialgoodindia.com/ Acesso em 17 de abril de 2014.

KANNAN, Shilpa. The low cost technology saving premature babies' lives. Disponível na internet por: <http://www.bbc.com/news/business-23817127/>. Acesso em 25 de maio de 2014.

LAMY, Zeni Carvalho et al. Atenção humanizada ao recém-nascido de baixo peso Método Canguru: a proposta brasileira. Ciência e Saúde Coletiva, v. 10, n. 3, p. 659-68, 2005.

MALAGUTI, Cyntia Santos. Design e valores materializados - cultura, ética e sustentabilidade. In: De Moraes, Dijon; Krucken, Lia. (Org.). Cadernos de Estudos Avançados em Design Sustentabilidade I. Barbacena: Editora da UEMG, 2009, v. 1. MANZINI, EZIO. Social Innovation and sustainability. How social innovation can change the world. Apresentação de slides. 2010. 
. Design para inovação social e sustentabilidade. Comunidades

criativas, organizações colaborativas e novas redes projetuais. Rio de Janeiro, E-papers, 2008.

MARGOLIN, Victor. O Designer Cidadão. In: Revista Design em Foco. 2006, vol. III. MCCARTHY, Jeffrey. The Embrace Infant Warmer for the Treatment of Hypothermia in Resource Limited Settings. BCPP Biomedical Engineering, University of Rhode Island, BME 281 First Presentation, 2013.

MERONI, Anna. Creative communities: People inventing sustainable ways of living. Milano: Edizioni POLI.Design, 2007.

MURRAY, Robin; CAULIER-GRICE, Julie; MULGAN, Geoff. The open book of social innovation. National Endowment for Science, Technology and the Art, 2010.

MURUGANANTHAM, Arunachalam (Entrevista). In: SEAH, Kui Luan e VIRMANI, Amit. The Menstrual Man. [Filme-Vídeo]. Produção de Kui Luan Seah e Amit Virmani, Direção de Amit Virmani. Singapura, 2013. DVD, 63 minutos. Documentário.

Nasscom Foundation (site). Disponível na internet por www.nasscomfoundation.org/get-engaged/nasscom-social-innovation-honours/pastwinners/winners-2014.html. Acesso em 18 de junho de 2014.

Organização Mundial de Saúde. Método Madre Canguru: Guia Práctica. Genebra, 2004.

PanlIT Conclave 2010 Healthcare: Reaching out to the masses (relatório). Disponível na internet por http://www.kpmg.de/docs/Healthcare_in_India.pdf. Acesso em $18 \mathrm{de}$ junho de 2014.

SACHS, Ignacy. Barricadas de ontem, campos de futuro. Revista Estudos Avançados: São Paulo. 24 (68): 25-38, 2010.

SEAH, Kui Luan e VIRMANI, Amit. The Menstrual Man. [Filme-Vídeo]. Produção de Kui Luan Seah e Amit Virmani, Direção de Amit Virmani. Singapura, 2013. DVD, 63 minutos. Documentário.

SHANMUGALINGAM, Cynthia. Six innovators I met in India. Apresentação de slides. Young Foundation, 2009.

Sughavazhu. Disponível na internet por http://www.sughavazhvu.co.in/. Acesso 18 de junho 2014.

Times of India (revista). Disponível

$<$ http://timesofindia.indiatimes.com/tech/enterprise-it/strategy/US-pro-immigrationfor-talented-people-Gururaj-Deshpande/articleshow/21720975.cms?referral=PM>.

Acesso em 18 de junho de 2014.

VENEMA, Vibeke. Conheça o homem que 'adotou um útero' e iniciou uma revolução na Índia. Disponível na internet por <http://www.geledes.org.br/areas-deatuacao/questoes-degenero/265-generos-em-noticias/23743-conheca-o-homem-queadotou-um-utero-einiciou-uma-revolucao-na-india $>$. Acesso em em 10 de abril de 2014.

VERGANTI, Roberto. Design-Driven Innovation: Changing the Rules of Competition by Radically Innovating What Things Mean. 1ed, Boston: Harvard Business Press. 2009, 232p. 